\section{Organic Fertilization of Fresh Market Sweet Basil in a Greenhouse}

\author{
C. Elizabeth Succop and \\ Steven E. Newman ${ }^{1}$
}

AdDITIONAL INDEX WORDS. organoleptic, hydroponic, herbs, Ocimum basilicum

\begin{abstract}
Summary. Fresh-market sweet basil (Ocimum basilicum) is in high demand from specialty produce markets and commercial restauranteurs. Many consumers are also demanding produce that has been organically grown. Three hydroponic media systems were evaluated twice over two years, rockwool slabs, perlite frames, and commercial sphagnum peat/ perlite/compost medium, where the bag was laid flat on the bench. Plants grown in these systems were fertilized with nutrient solutions derived from either organic or conventional, saltbased fertilizer sources. Few differences in yield were detected between basil plants grown in the commercial medium with either fertilizer source. Total yield from plants grown in perlite with the organic fertilizer was $22 \%$ greater in the first study and $100 \%$ greater in the second study than those for plants grown with the conventional fertilizer. Plants grown in rockwool with the conventional fertilizer were $17 \%$ more productive in the first study and $46 \%$ more productive in the second study than those grown with the organic fertilizer. Taste test panelists $(69 \%)$ could discern differences between samples from organically and conventionally grown basil plants, yet no preferences were shown.
\end{abstract}

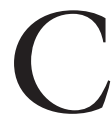
ommon green sweet basil is a choice crop for greenhouse production due to its high dollar value, popularity, and demand.

Department of Horticulture and Landscape Architecture, Colorado State University, Fort Collins, CO 80523-1173.

Funding was provided by the Colorado Floriculture Foundation and the Colorado Agricultural Experiment Station (project 642). The cost of publishing this paper was defrayed in part by the payment of page charges. Under postal regulations, this paper therefore must be marked advertisement solely to indicate this fact.

${ }^{1}$ Graduate student and associate professor, respectively.
Southern California restaurants listed basil as their top herb in popularity and in difficulty to obtain (Brown, 1991).

Organically and hydroponically grown products provide a marketing edge for growers (Marter, 1996). Greenhouse hydroponic organic growing methods can fulfill a need for locally grown organic produce during the winter months. Many popular herbs have the potential to grow up to $25 \%$ faster in a hydroponic solution, compared to soil (Skagg, 1996).

Studies on the quality of herbs grown with organic compared to conventional fertilizers have produced mixed results depending on the species and characteristics measured (Aflatuni, 1993). These characteristics included essential oil content, dry matter yields, percentage dry matter, plant height, plant development, and vigor. Our objectives were to determine if basil could be grown using organic fertilizers in a greenhouse and to determine if a discernable difference in taste could be detected between plants grown with organic and conventional fertilizers.

\section{Materials and methods}

This study was conducted at the W.D. Holley Plant Environmental Research Center fiberglass reinforced plastic (FRP) greenhouses on the Colorado State University campus (Fort Collins, Colo.). The greenhouse temperature was maintained with pad and fan evaporative cooling and steam heat. 'Siam Queen' basil seeds (Ball Seed Company, West Chicago, Ill.) were sown 11 June 1996 in $3.5 \times 3.5$ $\times 3.8-\mathrm{cm}(1.38 \times 1.38 \times 1.50$ inches $)$ rockwool multiblocks (AgroDynamics, East Brunswick, N.J.) with a 1-cm (0.4inch) hole, and placed under intermittent mist for $20 \mathrm{~d}$. On 22 July 1996, the plants in multiblocks were transferred to the FRP greenhouse and placed onto three root-zone media. The average mid-day temperature was $28.9 \pm 5.0$ ${ }^{\circ} \mathrm{C}$ day $\left(84 \pm 9^{\circ} \mathrm{F}\right)$ and $20.0 \pm 2.2^{\circ} \mathrm{C}$ night $\left(68 \pm 4^{\circ} \mathrm{F}\right)$.

The three hydroponic media systems compared were: rockwool slabs, perlite frames, and commercial sphagnum peat/perlite/compost (PPC) medium. The rockwool (RW) slabs (AgroDynamics, East Brunswick, N.J. $)$ were $15 \times 8 \times 91 \mathrm{~cm}(5.9 \times 3.1 \times$ 35.8 inches) and covered with polyethylene. Frames containing perlite (PL) were $91.4 \times 18.4 \times 132.1 \mathrm{~cm}(36 \times 7$ $1 / 4 \times 52$ inches $)$ and constructed from pine lumber. The perlite was filled to $17.1 \mathrm{~cm}$ (6.75 inches). The $39.6 \mathrm{~L}$ $\left(1.4 \mathrm{ft}^{3}\right)$ PPC medium bags were 48.3 $\times 15.2 \times 76.2 \mathrm{~cm}(19 \times 6 \times 30$ inches $)$ and laid flat on a bench with a square hole cut in the polyethylene for plant placement. RW and PL were chosen due to their common use as media in hydroponic food production. The PPC medium was chosen to compare conventional hydroponic media with an alternative yet convenient medium. The PPC medium was a proprietary blend of sphagnum peat moss, perlite, and compost consisting of construction wood waste and poultry (layer hens with no bedding) manure (Organix, Platteville, Colo.).

Table 1. Nutrient concentrations of the conventional and organic fertilizer sources compared to a recommended fertilizer solution for greenhouse production of fresh market basil.z

\begin{tabular}{lccc}
\hline & \multicolumn{3}{c}{ Nutrient concn $\left[\mathrm{mg} \cdot \mathrm{L}^{-1}(\mathrm{ppm})\right]$} \\
\cline { 2 - 4 } Element & Conventional & Organic & Recommended $^{\mathbf{y}}$ \\
\hline Nitrogen & 364 & 369 & 210 \\
Phosphorus & 78 & 78 & 80 \\
Potassium & 308 & 280 & 275 \\
Calcium & 119 & 107 & 180 \\
Magnesium & 81 & 68 & 80 \\
Sulfur & 426 & 818 & 200 \\
Manganese & 0.80 & 0.80 & 0.25 \\
Iron & 3.75 & 3.72 & 3.75 \\
Copper & 0.78 & 0.78 & 0.26 \\
Boron & 0.26 & 0.26 & 0.60 \\
Zinc & 2.66 & 2.67 & 0.25 \\
Molybdenum & 0.06 & $0.00^{\mathrm{x}}$ & 0.06 \\
Sodium & 44 & 44 & $\mathrm{NA}$ \\
\hline
\end{tabular}

${ }^{z}$ Nutrient analyses conducted by the Soil and Crop Sciences Department Soil, Water and Plant Testing Laboratory, Colorado State University, Fort Collins, Colo.

y'As recommended by AgroDynamics's Hydroponic nutrient fertilizer growing guide. (AgroDynamics, 1988). ${ }^{x}$ Below detectable limits. 
Table 2. Analysis of variance for fresh market basil study conducted in 1996 grown with either conventional or organic fertilizer sources and three production systems: commercial sphagnum peat/perlite/compost medium (PPC), perlite, or rockwool based on 16 weeks of harvesting.

\begin{tabular}{lrrrr}
\hline $\begin{array}{l}\text { Source of } \\
\text { variation }\end{array}$ & df & $\begin{array}{c}\text { Mean } \\
\text { square }\end{array}$ & $\begin{array}{c}\text { F } \\
\text { value }\end{array}$ & $\boldsymbol{P}>\mathbf{F}$ \\
\hline Block & 2 & 17,444 & 3.79 & 0.0595 \\
Fertilizer source (FS) & 1 & 139 & 0.03 & 0.8655 \\
Media $(\mathrm{M})$ & 2 & 2,961 & 0.64 & 0.5459 \\
FS $\times$ M & 2 & 9,501 & 2.06 & 0.1775 \\
Block $(\text { FS } \times \text { M })^{\mathrm{z}}$ & 10 & 4,601 & 10.57 & 0.0001 \\
$\quad$ Harvest date $(\mathrm{HD})$ & 18 & 77,317 & 177.56 & 0.0001 \\
$\quad \mathrm{FS} \times \mathrm{HD}$ & 18 & 1,271 & 2.92 & 0.0001 \\
$\mathrm{M} \times \mathrm{HD}$ & 36 & 1,524 & 3.50 & 0.0001 \\
$\quad \mathrm{FS} \times \mathrm{M} \times \mathrm{HD}$ & 36 & 905 & 2.08 & 0.0002 \\
Error & 3,828 & 435 & & \\
\hline
\end{tabular}

${ }^{2}$ Error A, which was used to test the effects: block; fertilizer source; media; and the interaction between fertilizer source and media.

'Error B, which was used to test the effects: block within fertilizer source and media; harvest date; and the interactions between fertilizer source and harvest date, media and harvest date and fertilizer source, media and harvest date.

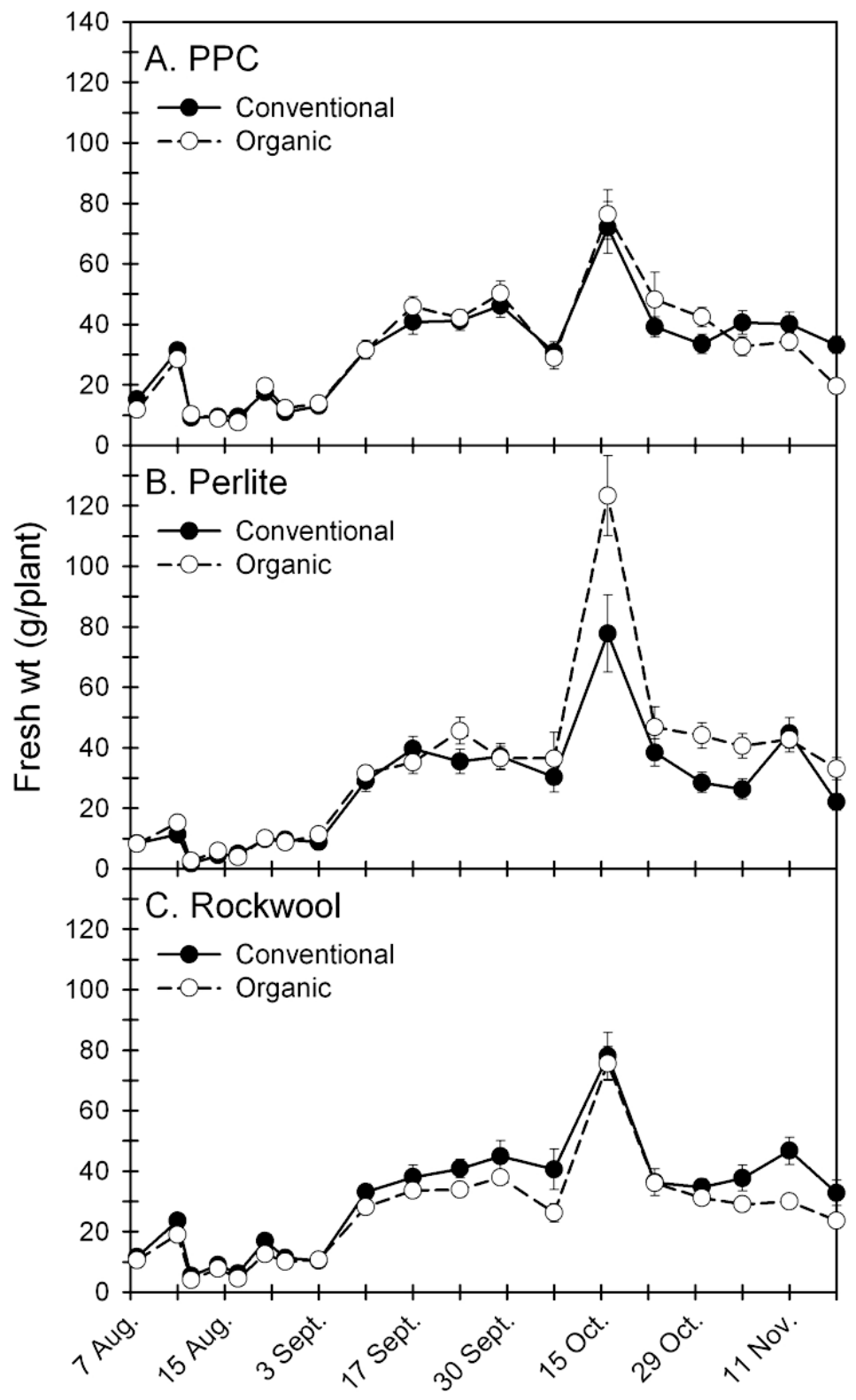

Harvest dates (1996)
Two hydroponic fertilizer formulations were compared. The first was an organic fertilizer liquid mixture and the second was derived from conventional fertilizer reagents. The organic fertilizer (Natural Source, United Environmental Technologies Inc., Sterling Colo.) consisted of organic fermented poultry compost (mixed layer and broiler with no litter), hydrolyzed fish emulsion, kelp extracts, and soft rock phosphate in a proprietary blend (Table 1). The final dilution was based on recommended nutrient levels for basil (AgroDynamics, 1988); however, high nitrogen $(\mathrm{N})$ levels were necessary to achieve adequate macro elements as well as minor elements. The conventional fertilizer-based solution was formulated to match the final organic solution as closely as possible by modifying Hoagland's recipe (Hoagland and Arnon, 1950) (Table 1).

An electronic irrigation controller managed the irrigation schedule and a dual tank fertilizer injector system was used to proportion the nutrient solutions. The irrigation/nutrient solutions were distributed to each plant in the RW and PPC medium by basket stake emitters with a $45.7-\mathrm{cm}$ (18-inch) leader (Netafim, AgroDynamics, East Brunswick, N.J.) where the water pressure was reduced to $137.9 \mathrm{kPa}(20 \mathrm{psi})$. Plants grown in the PPC and RW were irrigated with the fertilizer solutions four times daily for a 2 -min duration or $130 \mathrm{~mL}$ ( $4.4 \mathrm{fl}$ $\mathrm{Oz}$ ) of solution. Plants in the PL beds were irrigated with $180^{\circ}$ perimeter spray emitters arranged in a manner to allow for uniform coverage at the same intervals as previously described, however, the PL beds were maintained on a separate zone with similar volumes per plant throughout the study, yet this treatment required some additional hand watering during the early stages for plant establishment.

Basil plants were grown on six wooden benches, $1 \times 4.3 \mathrm{~m}(3.3 \times$ $14 \mathrm{ft}$ ). Each bench had all three media

Fig. 1. Weekly harvest from 7 Aug. 1996 to 18 Nov. 1996 of greenhousegrown fresh market basil subjected to either conventional or organic fertilizer sources growing in $(\mathrm{A})$ commercial sphagnum peat/perlite/compost medium (PPC), (B) perlite, or (C) rockwool $(\mathrm{lg}=0.035 \mathrm{oz})$. Vertical bars represents the standard error of the mean where $n=12$. 
Table 3. Total harvest of fresh market basil per plant grown with either conventional or organic fertilizer sources and three production systems: commercial sphagnum peat/perlite/compost medium (PPC), perlite, or rockwool. The 1996 total yield was based on 16 weeks of harvest.

\begin{tabular}{lcc}
\hline \multirow{2}{*}{ Medium } & \multicolumn{2}{c}{ 1996 Total harvest per plant $(\mathrm{g})$} \\
\cline { 2 - 3 } & \multicolumn{1}{c}{ Conventional } & Organic \\
\hline PPC & $555(34.7)^{\mathrm{z}} \mathrm{a}^{\mathrm{y}}$ & $505(31.6) \mathrm{ab}$ \\
Perlite & $458(28.6) \mathrm{a}$ & $557(34.8) \mathrm{a}$ \\
Rockwool & $544(34.0) \mathrm{a}$ & $446(27.9) \mathrm{b}$ \\
\hline
\end{tabular}

${ }^{2}$ Average harvest per week and plant in parentheses $(1 \mathrm{~g}=0.035 \mathrm{oz})$.

${ }^{\mathrm{Y}}$ Means in columns with similar letters were not different as determined by the Fisher's least significant difference test at $P \leq 0.05$

Table 4. Analysis of variance for fresh market basil study conducted in 1997 grown with either conventional or organic fertilizer sources and three production systems: commercial sphagnum peat/perlite/compost medium (PPC), perlite, or rockwool based on 18 weeks of harvesting.

\begin{tabular}{lrrrr}
$\begin{array}{l}\text { Source of } \\
\text { variation }\end{array}$ & df & $\begin{array}{c}\text { Mean } \\
\text { square }\end{array}$ & $\begin{array}{c}\text { F } \\
\text { value }\end{array}$ & $\boldsymbol{P}>$ F \\
\hline Block & 2 & 11,037 & 5.96 & 0.0198 \\
Fertilizer source $(\mathrm{FS})$ & 1 & 3,706 & 2.00 & 0.1876 \\
Media $(\mathrm{M})$ & 2 & 27,652 & 14.93 & 0.0010 \\
$\mathrm{FS} \times \mathrm{M}$ & 2 & 37,537 & 20.26 & 0.0003 \\
Block $(\mathrm{FS} \times \mathrm{M})^{\mathrm{z}}$ & 10 & 1,852 & 7.34 & 0.0001 \\
$\quad \mathrm{Harvest}$ date $(\mathrm{HD})$ & 17 & 38,364 & 152.12 & 0.0001 \\
$\quad \mathrm{FS} \times \mathrm{HD}$ & 17 & 994 & 3.94 & 0.0001 \\
$\quad \mathrm{M} \times \mathrm{HD}$ & 34 & 1,303 & 5.17 & 0.0001 \\
$\quad \mathrm{FS} \times \mathrm{M} \times \mathrm{HD}$ & 34 & 1,822 & 7.23 & 0.0001 \\
Error $^{\mathrm{y}}$ & 3,765 & 252 & & \\
\hline
\end{tabular}

${ }^{z}$ Error A, which was used to test the effects: Block; Fertilizer source; Media; and the interaction between Fertilizer source and Media.

Error B, which was used to test the effects: Block within Fertilizer source and Media; Harvest date; and the interactions between Fertilizer source and Harvest date, Media and Harvest date and Fertilizer source, Media and Harvest date.

treatments each measuring $0.8 \times 1.3$ $\mathrm{m}(2.62 \times 4.27 \mathrm{ft})$ and one of the two fertilizer treatments. This combination was replicated three times for a total of 18 experimental units. Hydroponic organic basil producers in California space their plants at $12.7 \mathrm{~cm}$ (5 inches) centers (Schoenstein, 1996) compared to a conventional, soil-based, spacing of 30.5 to $45.7 \mathrm{~cm}$ (12 to 18 inches). Adjusting for the media systems evaluated, we adjusted our spacing to 22.9 $\mathrm{cm}$ (9 inches) on center with rows 22.9 $\mathrm{cm}$ apart allowing similar root-zone volumes. Each experimental unit had 12 plants for a total of 216 plants.

For typical basil production, harvesting the terminal leaves once or twice per week is ideal for a high quality basil product with little stem tissue (Davis, 1991). New growth, 5.1 to $10.2 \mathrm{~cm}$ (2 to 4 inches), was harvested weekly from the growing points of each plant. The first harvest, which initiated branching, occurred when four pairs of true leaves remained after cutting and prior to bloom appearance (Davis, 1991). The split-plot experiment was organized as a randomized complete- block design in which the two fertilizer treatments were whole plots and the three medium treatments were subplots. Weekly harvests were analyzed using a repeated measures design and fresh weight data were analyzed by analysis of variance with Fisher's least significant difference test on the main effect means for media.

The study was repeated in 1997 with minor adjustments to improve the plant growing environment. Basil plants were derived from rooted cuttings (Welby Gardens, Inc., Denver, Colo.). On 10 Mar. 1997 rooted basil cuttings grown in a soilless peat medium were transplanted from cell packs into RW grow blocks and placed onto their respective medium as previously described for 1996. The greenhouse temperature averaged $20.0 \pm 6.7^{\circ} \mathrm{C}$ day $\left(68 \pm 12{ }^{\circ} \mathrm{F}\right)$ and $15.0 \pm 2.2^{\circ} \mathrm{C}$ night $\left(59 \pm 4^{\circ} \mathrm{F}\right)$. Harvest data were collected from 18 Mar. 1997 through 28 July 1997. All data were analyzed as previously described; however, the two studies were not combined in the analysis as there were marked seasonal variation between the two studies.
Two taste tests were conducted to evaluate the taste differences and taste preferences for the organically and conventionally grown plants. The first test conducted was a triangle difference test (Kramer and Twigg, 1962) to determine whether there was a difference in taste between the organically grown basil and the conventionally grown basil. All samples were harvested the day prior to testing and stored over night in a cooler at $15{ }^{\circ} \mathrm{C}$ (Lange, 1994). Immediately before presenting the samples to the tasters, leaves were macerated with a kitchen blender. This process eliminated any size or visual differences between the samples. The samples, $29.6 \mathrm{~mL}$ ( $1 \mathrm{floz}$ ), were placed into plastic cups labeled with a random three-digit number and presented to a taste panel from the Department of Food Science and Human Nutrition, Colorado State University.

Each panel member was given three samples: two of the samples were the same. The panel members checked on a sheet of paper the sample identification number that corresponded to the sample they believed to be different. Twelve panel members evaluated the difference between the organically fertilized plants and the conventionally fertilized plants grown in the PPC medium. Seven panel members evaluated the difference between the organically fertilized plants and the conventionally fertilized plants grown in RW. Seven panel members evaluated the difference between the organically fertilized plants and the conventionally fertilized plants grown in PL.

After the panel members detected a difference between basil samples, a ranked preference test was conducted. The ranking test was conducted to determine whether a difference existed between samples with regard to degree of acceptability or general quality (Amerine, 1965). Twenty-nine panel members were given four samples to rank in order of preference. The four samples were from plants grown in the PPC medium with conventional fertilizer, plants grown in the PPC medium with organic fertilizer, plants grown in RW with conventional fertilizer, and plants grown in RW with organic fertilizer. At the time of the taste test, the plants grown in PL were not yielding adequately for analysis. The panel members were instructed to use any of their senses to determine a preference. The panel members ranked from 


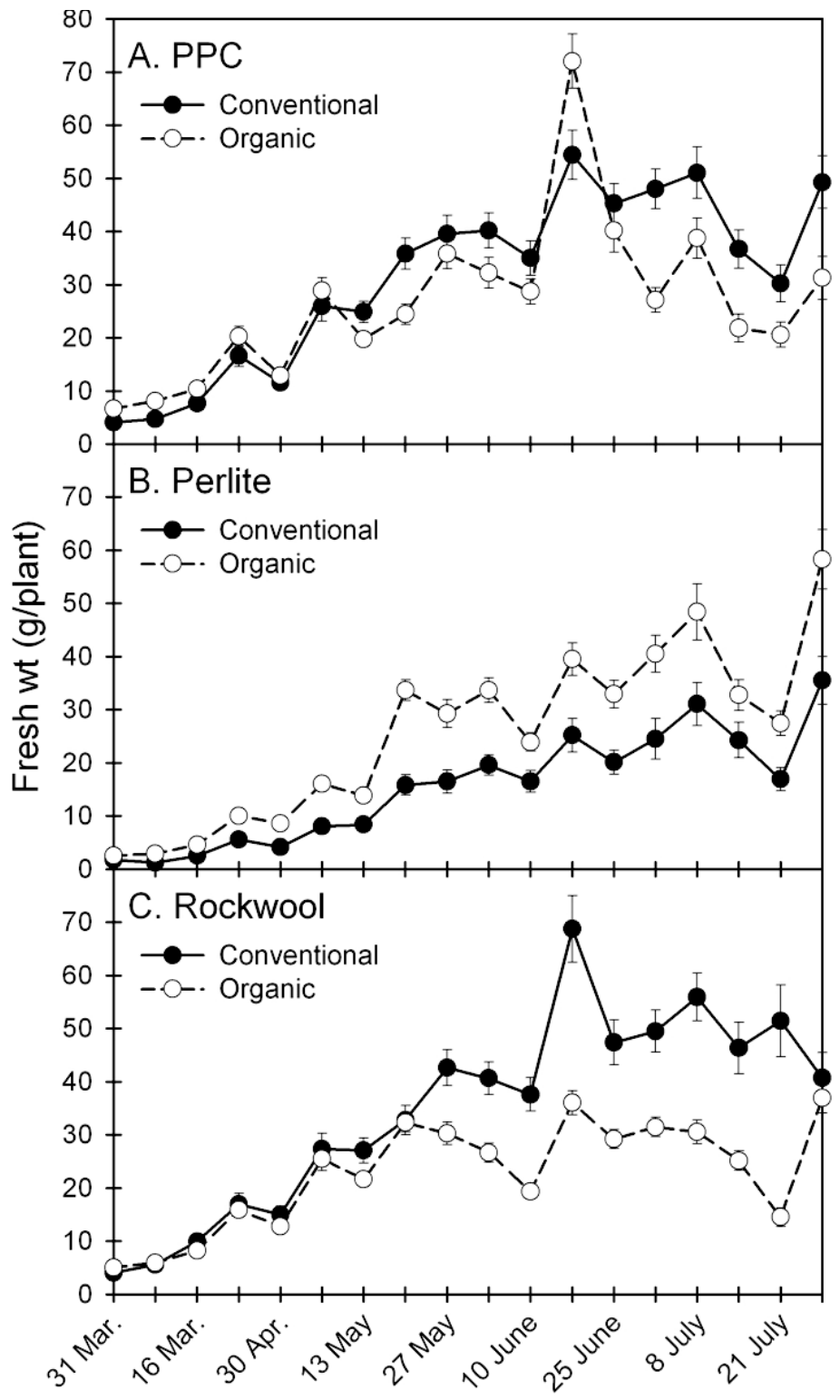

Harvest dates (1997)

Fig. 2. Weekly harvest from 31 Mar. 1997 to 28 July 1997 of greenhousegrown fresh market basil subjected to either conventional or organic fertilizer sources growing in (A) commercial sphagnum peat/perlite/compost medium (PPC), (B) perlite, or (C) rockwool $(1 \mathrm{~g}=\mathbf{0 . 0 3 5} \mathrm{oz})$. Vertical bars represents the standard error of the mean where $n=12$.

one to four the sample identification numbers, which corresponded to an order of preference ( 1 , least preferred to 4 , most preferred).

\section{Results and discussion}

There was an interaction between fertilizer source, media and harvest date where $P \leq 0.05$ (Table 2 ). Yields during the 1996 study were greatest 8 weeks after transplanting and remained high until after 15 weeks when the plants began to decline (Fig. 1). Yield at 15 weeks was markedly greater than the rest due to missing a regularly scheduled harvest. Late in the study, natural light, intensity and photoperiod, declined seasonally contributing to reduced plant growth. There were few differences between the effects of the fertilizer sources except towards the end of the study where the yield from plants grown with the conventional fertilizer was greater than that of those grown with the organic fertilizer source (Fig. 1).

Basil plants grown on PL with the organic fertilizer were more productive than those grown on RW with conventional fertilizer source, but similar to those grown on the PPC medium (Table 3). PL has a high level of porosity and aeration. Thus, oxygen may have been available to enable the decomposition of organic fertilizer. Natural Source is produced via a proprietary fermentation extraction process, which may have allowed a portion of the total percent of $\mathrm{N}$ to be immediately available in the nitrate- $\mathrm{N}$ and ammonium- $\mathrm{N}$ forms. $\mathrm{N}$ from typical organic sources becomes available over time (Foth and Ellis, 1988) improving the root-zone and enhancing rhizosphere microbial activity (Smith and Hadley, 1989). Therefore, the high aeration and high drainage capacity characteristics of PL may have allowed for the microbial decomposition process and subsequent increase in plant productivity over time.

The study described above was repeated in the spring of 1997 and during the first few weeks of growth, the plants grown in the PPC medium with the organic fertilizer source established more quickly than the plants in the RW or PL systems. This was indicated by faster rooting of the basil plants from the RW cube into the medium. There was an interaction between fertilizer source, media and harvest date where $P$ $\leq 0.05$ (Table 4 ). Weekly harvests were collected from 31 Mar. 1997 through 28 July 1997. Light intensity and photoperiod increased during this period and is reflected by increasing weekly harvests (Fig. 2). Yet, visual health and plant structure of the basil plants began to decline after four months of weekly harvests.

Few differences between the fertilizer sources for basil plants grown in the 
Table 5. Total harvest of fresh market basil per plant grown with either conventional or organic fertilizer sources and three production systems: commercial sphagnum peat/perlite/compost medium (PPC), perlite, or rockwool. The 1997 total yield was based on 18 weeks of harvesting.

\begin{tabular}{|c|c|c|}
\hline \multirow[b]{2}{*}{ Medium } & \multicolumn{2}{|c|}{1997 Total harvest per plant (g) } \\
\hline & Conventional & Organic \\
\hline PPC & $555(30.1) \mathrm{a}$ & $478(26.6) \mathrm{a}$ \\
\hline Perlite & $229(12.7) \mathrm{b}$ & $459(25.5) \mathrm{a}$ \\
\hline Rockwool & $585(32.5)$ a & $399(22.2) \mathrm{a}$ \\
\hline
\end{tabular}

${ }^{2}$ Average harvest per week and plant in parentheses $(1 \mathrm{~g}=0.035 \mathrm{oz})$.

${ }^{\mathrm{Y}}$ Means in columns with similar letters were not different as determined by the Fisher's least significant difference test at $P \leq 0.05$

PPC medium were observed early in the study (Fig. 2A). Toward the end of the study, the yield tended to be slightly greater with the conventional fertilizer compared to the organic fertilizer. Differing from the 1996 study, there was an interaction between media and fertilizer sources where $P \leq 0.05$ (Table 4). Yield from plants grown on PL with the organic fertilizer source was greater than those plants grown on PL with the conventional fertilizer during the second study after three weeks of harvest (Fig. 2B). Plants grown in RW yielded similarly between the organic and conventional fertilizer sources for the first two months, but the conventionally fertilized plants were more productive than the basil plants grown with organic fertilizer for the remainder of the study (Fig. 2C). RW medium is traditionally used with conventional fertilizers and its low aeration and high water holding capacity compared to PL may make it unsuitable for oxygen driven microorganism activity to occur. Organic fertilizers require consistent microorganism activity for decomposition and release of nutrients.

The total yield of basil plants grown with conventional fertilizer and $\mathrm{PL}$ was less than the yield of plants grown in the PPC medium and RW (Table 5 ). The total yield from basil plants grown with the organic fertilizer were not different among the three media (Table 5). The organic fertilizer appeared to improve the rhizosphere of the PL medium as previously discussed.

Panel members determined that the organically fertilized plants were different in flavor from the conventionally fertilized plants for all three growing systems. The results from 26 panel members, revealed that $69.8 \%$ were able to determine the organically grown from conventionally grown basil for flavor $(P \leq 0.05)$. Subsequent tests from 29 panel members revealed no differences existed between organically fertilized and conventionally fertilized basil with regard to preference (data not shown). These results were not unexpected as many taste tests comparing organically and conventionally grown food have given inconsistent results (Basker, 1992). Hedonic ratings between organic and conventional produce showed no taste differences, except for mangoes and orange juice (the conventionally grown products were preferred over organic) and bananas (organic were preferred over the conventionally grown). A multi-year study comparing organically and conventionally grown tomatoes yielded inconsistent preferences as well (Yoshida, 1984). Our taste tests were conducted as a blind trial to avoid any halo-effect often observed when comparing produce grown under organic conditions. A halo-effect attaches a preconceived atmosphere of quality about a product in a positive or negative direction. The perception distortion theory was confirmed by the halo-effect results from a taste test comparing identical tomatoes with different origin labels (Alvensleben and Meir, 1990).

\section{Conclusions}

Our results demonstrated that basil can be grown in a greenhouse with organic fertilization for fresh market production. The PPC and the RW medium provided the most consistent results compared to PL, which suggests the most appropriate growing medium is that which best fits existing greenhouse conditions. The organic fertilizer source may have improved the rhizosphere in the PL medium, which suggests this to be a good combination; however, the organic fertilizer was satisfactory in the PPC mix as well.

\section{Literature cited}

Alvensleben, R. and T. Meir. 1990. The influence of origin and variety on consumer perception. Acta Hort. 259:151-161.

Aflatuni, A. 1993. The effect of manure composted with drum compost on aromatic plants. Acta Hort. 344:63-68.

AgroDynamics, 1988. Hydroponic nutrient fertilizer growing guide. AgroDynamics, East Brunswick, N.J.

Amerine, M. 1965. Principles of sensory evaluation of food. Academic Press, New York.

Basker, D. 1992. Comparison of taste quality between organically and conventionally grown fruits and vegetables. Amer. J. Alt. Agr. 7:129-136.

Brown, S. 1991. Culinary herb use in southern California restaurants. Calif. Agr. 45(1):4-6.

Davis, J. 1991. Basil. North Carolina Cooperative Extension Service, Leaflet No. 125 .

Foth, H. and B. Ellis. 1988. Soil fertility. Wiley, New York.

Hoaglund, D.R. and D.I. Arnon. 1950. The water-culture method for growing plants without soil. Calif. Agr. Expt. Sta. Circ. 347.

Kramer, A. and B. Twigg. 1962. Fundamentals of quality control for the food industry. AVI, Westport, Conn.

Lange, D. 1994. Postharvest shelf life of sweet basil (Ocimum basilicum). HortScience 29:102-103.

Marter, M. 1996. Supermarkets finding the time is ripe for organic food market to grow. Knight Ridder/Tribune News Service: 325 .

Schoenstein, G. 1996. Hydro-organics: growing basil during the off-season. Small Farm Today 13(1):39-42.

Skagg, K. 1996. The urban gardener. Amer. Horticulturist: 9-10.

Smith, S.R. and P. Hadley. 1989. A comparison of organic and inorganic nitrogen fertilizers: their nitrate- $\mathrm{N}$ and ammonium- $\mathrm{N}$ release characteristics and effects on the growth response of lettuce (Lactuca sativa L. cv. Fortune). Plant and Soil 115:135-144.

Yoshida, K. 1984. Taste of tomato fruits cultured with organic fertilizers in comparison with inorganic fertilizers. J. Jpn. Soc. Nutr. Food Sci. 37:115-121. 